\title{
Arquivos Pessoais no radar do Tempo Presente. Dimensões e possibilidades nos estudos acadêmicos
}

Personal Archives on the Present Time radar.

Dimensions and possibilities in academic studies

Archivos personales en el radar del Tiempo Presente.

Dimensiones y posibilidades en los estudios académicos

\author{
Maria Teresa Santos Cunha \\ Universidade do Estado de Santa Catarina (Brasil) \\ http://orcid.org/0000-0001-6200-6713 \\ http://lattes.cnpq.br/1895532605964830 \\ mariatsc@gmail.com \\ Doris Bittencourt Almeida \\ Universidade Federal do Rio Grande do Sul (Brasil) \\ http://orcid.org/0000-0002-4817-0717 \\ http://lattes.cnpq.br/5715085520250456 \\ almeida.doris@gmail.com
}

\section{Resumo}

Neste texto, discutem-se as condições de produção, conservação e utilização de arquivos pessoais de professores universitários, sujeitos dotados de intelectualidade, e suas inscrições na História da Educação, mediadas pela experiência investigativa da História do Tempo Presente. Tal abordagem contempla, em diferentes temporalidades, as dimensões e possibilidades dos arquivos pessoais desses educadores em que o estudo de tais trajetórias de vida no tempo presente, permite reconfigurações de passados. Salienta-se, igualmente, o uso desses documentos como meio de investigar ações individuais como coletivas que atravessaram a vida cotidiana e acadêmica de Balduíno Antonio Andreolla (UFRGS) e Walter Fernando Piazza (UFSC), entre as décadas de 1950 a 1990. Problematizar gestos intencionais de guardar papeis do passado permite pensar se tais experiências podem ser consideradas memoráveis nos percursos dos professores a ponto de ocuparem lugar em suas gavetas. Guardaram para não esquecerem? Seria a preservação um modo de buscarem, em vida, uma espécie de musealização de sua memória?

Palavras-chave: Arquivos pessoais. Profissão docente. História da Educação. História do Tempo Presente. 


\begin{abstract}
This text discusses the conditions of production, conservation and use of personal archives of university professors, subjects endowed with intellectuality, and their inscriptions in the History of Education mediated by the investigative experience of the History of Present Time. This approach contemplates, in different temporalities, the dimensions and possibilities of the personal archives of these educators in which the study of such life trajectories in the present time allows reconfigurations of pasts. It is also emphasized the use of these documents as a means of investigating both individual and collective actions that crossed the daily and academic life of Balduíno Antonio Andreolla (UFRGS) and Walter Fernando Piazza (UFSC), between the decades of 1950 to 1990. Does problem-like gestures of storing papers from the past allow us to wonder if such experiences can be considered memorable in teachers' journeys to the point of taking place in their drawers. Did they keep it so they wouldn't forget? Is preservation a way of seeking, in life, a kind of musealization of their memory?
\end{abstract}

Keywords: Personal files. Teaching profession. History of Education. History of the Present Time.

\title{
Resumen
}

Este texto analiza las condiciones de producción, conservación y uso de los archivos personales de los profesores universitarios, materias dotadas de intelectualidad, y sus inscripciones en la Historia de la Educación mediadas por la experiencia investigadora de la Historia del Tiempo Presente. Este enfoque contempla, en diferentes temporalidades, las dimensiones y posibilidades de los archivos personales de estos educadores en los que el estudio de dichas trayectorias de vida en el tiempo presente permite reconfiguraciones de pasados. También se destaca el uso de estos documentos como medio para investigar acciones individuales y colectivas que cruzaron la vida cotidiana y académica de los profesores Balduíno Antonio Andreolla (UFRGS) y Walter Fernando Piazza (UFSC), entre las décadas de 1950 hasta 1990. ¿Nos permiten preguntarnos si tales experiencias pueden considerarse memorables en los viajes de los maestros hasta el punto de tener lugar en sus cajones $i$ Lo guardaron para no olvidarlo? ¿Es la preservación una forma de buscar, en la vida, una especie de musealización de su memoria?

Palabras clave: Archivos personales. Profesión docente. Historia de la Educación. Historia del Tiempo Presente. 
O arquivo, antes de ser memória histórica, é memória da dominação constante de legados e atestações, de certificados que funcionam como provas dos direitos de poder, de posse e origem familiar [...] Controle do arquivo é controle da memória [...] é um armazenador coletivo de conhecimentos que desempenha diversas funções $[\ldots]$ que mantiveram seu valor como fontes para os historiadores. (ASSMANN, 2011, p.168).

\section{Introdução: Arquivos Pessoais e Tempo Presente}

Arquivos pessoais, para os historiadores, situam-se na clave de portadores de registros de memória e documentos de vida que podem funcionar, no tempo presente, como testemunhos de passados que constituem "a estrutura fundamental de transição entre a memória e a história" (RICOEUR,2007, p.41). Para além das iniciativas de organização, salvaguarda e conservação neles investidos, os arquivos pessoais mantêm, para a pesquisa historiográfica, seu valor de fonte, pois abrem múltiplas possibilidades de consulta para a construção de narrativas. Mais do que reunir documentos, fotos, objetos, equipamentos, eles, funcionam como bancos de dados além de "constituírem memória da nação e uma parte essencial de seu patrimônio histórico" (HARTOG, 2011, p.232), mesmo considerando sua construção como "um projeto coletivo, no qual se sobrepõem várias subjetividades, afastando-se da sedutora imagem de expressão fiel e autêntica da subjetividade do seu titular" (HEYMANN,2005).

Segundo os estudos de Heloísa Bellotto (2006), um arquivo pessoal ainda que tenha definições amplas, envolve, principalmente, um conjunto de papeis e material, seja audiovisual ou iconográfico, acumulados por uma pessoa durante o decurso de uma vida. $\mathrm{O}$ conhecimento, os registros e a experiência de pesquisa neste material constituem uma variada e potente fonte informativa que deve ser problematizada pelo ato de historiar e será esta a perspectiva de trabalho com os arquivos pessoais dos dois professores universitários.

Sem preconizar habilidades técnicas maiores (e muito bem realizadas pelos arquivistas de formação), intenta-se reconhecer, nos arquivos pessoais de professores aqui em destaque, suas possibilidades para a pesquisa historiográfica, pois são "objeto de história de pleno direito, em múltiplas dimensões (materiais, institucionais e intelectuais) e arquivistas e historiadores haveriam de tirar o maior proveito de refletir em comum a seu respeito". (HARTOG, 2011, p.237-238). Observa-se, neste material em estudo, variados documentos aparentemente desconexos, mas que atestam e ilustram seu caráter altamente heteróclito, nos quais se misturam o banal ao trágico, até mesmo o risível. Neles, como historiadoras pretendem-se realizar uma interpretação/análise, compondo aspectos daquelas vidas para nesse movimento dar "um significado de destaque como memória potencial ou pré-condição material para memórias culturais futuras" (ASSMANN, 2011, p.169).

Para trabalhar os arquivos pessoais como fontes foi fundamental traçar um caminho metodológico no sentido de pensar perguntas feitas às mesmas que podem ampliar o horizonte de possibilidades em torno deles para, a partir do presente, lançar-se aos passados possíveis. O ponto de partida envolve prescindir da utopia do sentido global e aplicar o esforço e a criatividade na tarefa modesta, e mais digna, de abrir caminhos e operar, não raro, por ensaio-e-erro, em aproximações sucessivas e com ideias e valores sem pretensão de totalidade. $\mathrm{O}$ trato com os arquivos pessoais exige certa ênfase na 
pesquisa empírica e não aceitação de explicações fáceis e apres sadas a fim de evitar riscos de modelos explicativos que ignoram as especificidades históricas no tempo e no espaço. Assim, pensá-los como documentos implica recusar de modo permanente o avanço das simplificações e, sobretudo, não distribuir certezas, mas instigar dúvidas e instrumentalizar para sua contestação a partir de demandas que emergem de seus percursos acadêmicos.

O que os arquivos pessoais, aqui escolhidos, parecem apontar é que o tempo não danifica os acontecimentos, pelo contrário, é ele que, requisitando sua análise, permite sua fixação imperecível sob a forma de memória. No trato com arquivos pessoais de professores nos quais esta investigação se sustenta, eles são considerados como lugares que acumulam camadas de tempo que permaneceram e se modificam, pela pesquisa atual, em velocidades próprias. Em vista disso, é o presente que se constitui em uma espécie de guia e, assim, conduz os gestos de analisar estes guardados.

Estas experiências presentes no trato com os arquivos pessoais que guardam um certo vivido dos sujeitos têm assolado a vida no tempo presente e afetado o "espaço de experiência" (KOSSELECK, 2014), considerado como um local que preserva um passado e que se concretiza no presente de múltiplas maneiras aquilo que ROUSSO (2016) caracterizou como "um passado que não está acabado [...] em que o sujeito da sua narração é um ainda ẩ" (p.18) Pode-se considerar que tais experiências neste campo têm, igualmente, demandado questões que abrem "horizontes de expectativas" (KOSELLECK, 2014) que, encontrados no presente, visam o futuro e interferem nas ações de mulheres e homens deste nosso tempo, afetando seus medos, interpretações ou realizações de sonhos, anseios, esperanças e, consequentemente, o modo de pesquisar e escrever história.

Para a consecução deste artigo, um dos imperativos foi considerar os arquivos pessoais como portadores de memórias e considerar, igualmente, a memória, por sua vez, como problema fundamental da história. O historiador tem o dever de memória (HARTOG, 2006, p.264), ele deve lembrar certas coisas, ser a garantia de uma intenção de verdade contra aqueles que querem apagar ou manipular a história: é sua função cívica, política e ética. Uma outra função é trabalhar com as outras ciências sociais no nosso espaço de experiência para construir, segundo a proposta de Koselleck (2014), o horizonte de expectativa, qual seja construir expectativas para o futuro. Sabe-se hoje que o futuro não está pré-escrito, há que construir uma inteligibilidade ao vivido já que não se sustenta mais, como se acreditava, que a história tem um sentido. Hoje, este sentido está por ser construído e ele nos reenvia ao presente, ao ainda aí. Temos, então, que torná-lo inteligível para encontrar os eixos das/para as construções futuras. O historiador deve ser o elo dessa passagem; deve estar muito atento ao presente, o presente é a categoria mestra para articular um futuro possível. Portanto, são as perguntas feitas no presente que demandarão as incursões aos arquivos pessoais dos dois professores. Os materiais guardados nestes arquivos ressoam, de alguma maneira no presente, pois é perceptível nos materiais que se leem, ecos que ficaram emudecidos e criam chances de se investir para compreender passados/presentes e mesmo os silêncios da memória.

O interesse, a curiosidade e o estudo destas problemáticas e por estes autores, foi um estímulo para articular documentos presentes em dois arquivos pessoais de docentes que atuaram em Universidades Federais, no Rio Grande do Sul (UFRGS) e em Santa Catarina (UFSC). Os documentos salvaguardados permitiram construir uma narrativa que juntou aspectos de ações tanto individuais como coletivas que atravessaram a vida cotidiana e acadêmica de Balduíno Andreola (UFRGS) e Walter Fernando Piazza (UFSC), entre as décadas de 1950 a 1990, permitiram, sobretudo, questionar as artes de guardar que levou a uma certa musealização de suas memórias, haja vista estarem alojados em locais públicos com consulta irrestrita. 


\section{1. $O$ arquivo Walter Fernando Piazza: Nos umbrais da pesquisa}

$\mathrm{O}$ arquivo apresenta-se assim como o lugar físico que abriga o destino dessa espécie de rastro que cuidadosamente distinguimos do rastro cerebral e do rastro afetivo, a saber o rastro documental (RICOEUR, 2007, p.177).

Considerados tanto polissêmicos (portadores de muitos significados) como polifônicos (com multiplicidade de vozes), os arquivos pessoais guardam rastros documentais de passados e podem ser concebidos como resultado do empenho de determinada personalidade ou mesmo pessoa comum em legar e até mesmo impor, ao futuro, uma imagem de si. Portadores de diferentes tipos de registros, abrem acesso ao que se chama de passado. Neles, tudo merece ser lembrado, pois ouvir as vozes que emergem desses registros é abrir-se e estar atentos a outras formulações. Como em uma partitura musical, materiais preservados devem ser analisados e executados, ganhar vida na interpretação daqueles que lhe emprestam mais do que olhos e ouvidos; qual seja, transformar inquietações em interesses. Cabe, então, ao pesquisador construir as perguntas para as quais documentos armazenados podem se tornar uma resposta. Afinal, se os arquivos são essenciais, as possibilidades de historiá-los também o são. O que não deixa de ser um consolo para os pesquisadores.

No intuito de situar a personagem cujo arquivo pessoal tem o protagonismo deste artigo, é fundamental delinear aspectos da trajetória do Professor Walter Fernando Piazza. Catarinense, nasceu em 06 de novembro de 1925 na cidade de Nova Trento e faleceu em 09 de fevereiro de 2016, na cidade de Florianópolis. Foi, desde a década de 1960, professor da Universidade Federal de Santa Catarina (UFSC), tendo suas principais pesquisas versando acerca da cultura popular, folclore, fluxos migratórios e arqueologia do estado de Santa Catarina. Foi o criador e primeiro Coordenador do Programa de PósGraduação em História, em 1975, além de ser professor da Universidade do Estado de Santa Catarina (UDESC) e da Universidade do Vale do Itajaí (UNIVALI), em Santa Catarina. Também cabe destacar sua atuação como Presidente do Instituto Histórico e Geográfico de Santa Catarina (IHGSC) e membro de várias instituições de pesquisa histórica nacionais e internacionais, como o Instituto Histórico da Ilha Terceira, nos Açores (Portugal). Na década de 1960, participou do Programa Nacional de Pesquisas Arqueológicas, realizando um levantamento em Santa Catarina, incluindo o Vale do Chapecó, o Rio Uruguai, o vale do Rio do Peixe e o vale do Itajaí. Deixou vasta obra sobre a História de Santa Catarina ${ }^{1}$.

\footnotetext{
${ }^{1}$ Dados biográficos retirados de sua biografia disponível no site do IDCH/UDESC. Consultado em23 out. 2010. Disponível em: https://www.udesc.br/arquivos/faed/id_cpmenu/1006/Biografia_Piazza_1563796515564_1006.pdf
} 
Foto 1: Professor Walter Fernando Piazza

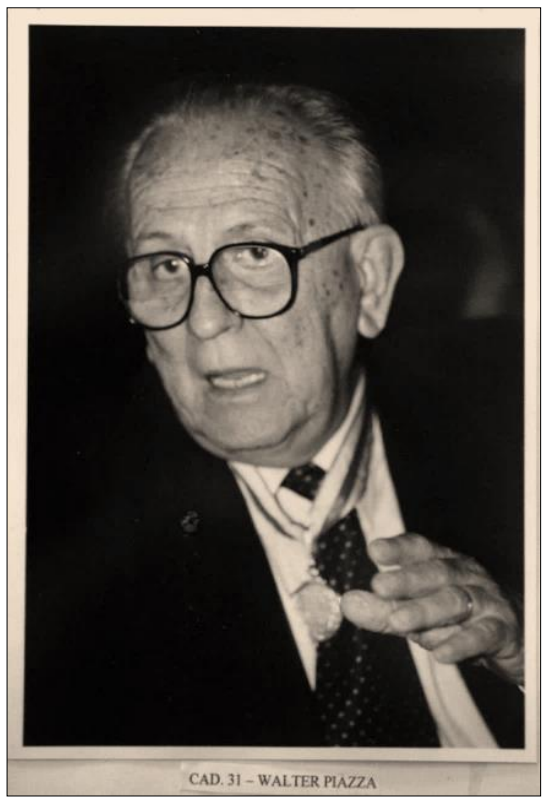

Fonte: Arquivo Piazza/IDCH/UDESC/ 2018

Seu arquivo pessoal foi doado, pela família, em 2016, ao Instituto de Documentação e Investigação em Ciências Humanas $(\mathrm{IDCH})^{2}$ ligado à UDESC e está disponível, com cerca de cinco mil peças, já digitalizado, para consulta online. ${ }^{3}$ Os materiais doados compõem um rico conjunto documental (livros, revistas, diplomas, agendas pessoais, fotos, cartas, etc.) além de objetos e honrarias recebidas ao longo de sua carreira. Este arsenal de documentos chegou ao IDCH em caixas e organizados pelas três filhas (uma historiadora, uma bibliotecária e uma arquiteta) e permitem pensar na possibilidade de um processo de triagem/seleção, comuns na doação de arquivos pessoais.

Os estudos da historiadora Angela de Castro Gomes (1998), que envolvem arquivos pessoais, evidenciam a "ilusão da verdade" e destacam as preocupações recorrentes com as técnicas de interpretação e exegese que não dispensam a metáfora e a imagem e levam ao interesse pela história do arquivo como experiência de guardar, de memória e de (re) conhecimento. Segundo esta autora, a proximidade com que o pesquisador lida com os documentos pode induzir à ilusão de que os escritos são "'espontâneos", "'autênticos" ou portadores de" verdade", desconsiderando que eles foram ' construídos por um autor e que se transformam ao longo do tempo, assumindo formas e até cores diferenciadas" (1998, p. 126). Selecionados e entregues ao IDCH, é fundamental reconhecer, portanto, desde uma parcialidade no recorte, feito pelo pesquisador no trato documental até uma provável seleção realizada pela família, situações corriqueiras que borram tentativas de produzir um conhecimento absoluto sobre o tema, ainda que não sejam impeditivos para a pesquisa.

A trajetória de Walter Fernando Piazza comporta o exercício e, não raro, o acúmulo de funções administrativas e educacionais e a interação entre pesquisa, docência e formação de

\footnotetext{
${ }^{2}$ O Instituto de Documentação e Investigação em Ciências Humanas - IDCH tem por objetivo ser um centro de documentação destinado a desenvolver pesquisas, receber, tratar, armazenar acervos e documentos em diversos suportes, estimulando a produção, socialização e estruturação de conhecimento gerado na área de Ciências Humanas pela comunidade científica da FAED e pela comunidade externa. Situa-se à Rua Visconde de Ouro Preto, 475, no centro de Florianópolis e, atualmente, é coordenado pela Prof ${ }^{a}$ Dra. Fernanda de Sales. Disponível https://www.udesc.br/faed/idch. Acesso em 21 out. 2020.

${ }^{3}$ https://www.udesc.br/faed/idch/cole\%C3\%A7\%C3\%B5es/piazza
} 
novos profissionais, aliado à interlocução com historiadores estrangeiros ${ }^{4}$ (portugueses e norteamericanos, em especial) que lhe deram possibilidades de participação em um programa de projeção internacional, além de contatos com brasilianistas que, entre 1976 e 1980, integraram os quadros do Programa de Pós-Graduação em História da Universidade Federal de Santa Catarina ${ }^{5}$. Tais protagonismos permitem pensá-lo como um praticante de mediação cultural, também chamado de intelectual mediador (GOMES, 2016).

reconhecemos que as práticas de mediação cultural podem ser exercidas por um conjunto diversificado de atores, cuja presença e importância nas várias sociedades e culturas têm grande relevância, porém, sem sempre reconhecimento (p.9)

Alojados no arquivo pessoal de Walter Fernando Piazza, resquícios e pormenores de uma vida encontram-se materializados em documentos escritos e objetos que realçam uma memória de sua atuação, suas leituras, ações efetivas, prazos cumpridos. A singularidade e certa originalidade do percurso do Professor Piazza o singulariza diante dos demais membros de sua geração em Santa Catarina e está vinculada à atenção que concedeu à pesquisa em arquivos, à guarda de documentos em papel, que mantêm seu valor como fontes para os pesquisadores.

\subsection{No arquivo de Walter Fernando Piazza: Agendas em um frenesi documental}

Independente das peripécias da história documental - positivismo ou não - o frenesi documental apoderou-se da época (RICOEUR, 2007, p.179)

Os documentos do arquivo Piazza, encarnam e despertam uma certa magia, seja pela ordem como foram dispostos, seja pelo cuidado ao ser doado já com uma organização documental feita pelas filhas cuja logística foi mantida na sala a ela destinada junto à Instituição que o recebeu (IDCH/UDESC) e, sobretudo, pelos documentos e objetos que o integram. Por estarem disponíveis à consulta em uma instituição custodiadora e de salvaguarda evocam tanto um "frenesi documental" como "uma pedagogia da memória, isto é, de um enquadramento da cultura da memória por um projeto educativo" (RICOEUR, 2007, p.81). Considerar este arquivo como um projeto educativo, envolve reconhecer que, através dele, é possível realizar estudos e mobilizar procedimentos técnicos e imaginativos para explorar fontes documentais que abordem uma dimensão educativa e se revestem de importância para a História da Educação catarinense e brasileira, entre as décadas de 1950 a 1990.Considera-se, também, seu caráter de patrimônio histórico-educativo, evidência garantida tanto pelo seu alto valor documental como por estar salvaguardado em uma instituição pública do Estado que lhe dá proeminência. Os embates presentes entre o momento entre a doação/seleção pela família e organização feita quando instalado no arquivo se constituem como parte de um processo de musealização que inclui a construção e consolidação de uma memória (CUNHA, 2019, p.78).

Alojadas em sala especial no IDCH/UDESC, hospedam-se livros, revistas, documentos especiais e uma infinidade de outros materiais que já estão todos catalogados e disponíveis à consulta pública. Heterodoxas e enigmáticas, envoltas em aparente banalidade, agendas pessoais, certificados variados, planos de aula e de curso, cartas, honrarias, rascunhos de publicações direcionam o olhar para estes documentos ditos ordinários ou avulsos e que

\footnotetext{
${ }^{4}$ Programa Nacional de Pesquisas Arqueológicas (PRONAPA) (1965-1970) coordenado por Clifford Evans e Betty Meggers, do Smithsonian Institute, sediado em Washington.

${ }^{5}$ Professores Lawrence James Nielsen, George Brown e Robert Colson.
} 
propiciam a emergência de um conjunto de questões que têm como horizonte a perspectiva de mapear o terreno de práticas culturais e docentes do seu titular.

Neste primeiro momento, nos umbrais do arquivo, investimentos iniciais de imersão no arquivo estão a ser realizados mostrando sua inserção dinâmica no cenário historiográfico catarinense e brasileiro do período ${ }^{6}$ e dando visibilidade a materiais/documentos que subsidiarão futuras pesquisas. Foi realizado um primeiro levantamento geral dos documentos ditos avulsos (ofícios, correspondências, honrarias, certificados de eventos, ofícios, e folhas diversas) que totalizaram 1338peças e contribuem para desenhar os contornos do arquivo que se compõe de materiais que anunciam diferentes formas de comunicação e oferecem pistas curiosas para pesquisas a respeito do universo cultural em que Piazza estava imerso.

Quadro 1: Tipologia de Papeis Avulsos

\begin{tabular}{|c|c|c|}
\hline Tipologia documental & Período & Quantidade \\
\hline Correspondências & $1949-1999$ & 989 \\
\hline Certificados & $1960-2010$ & 12 \\
\hline Honrarias & $1960-1995$ & 13 \\
\hline Ofícios & $1951-2002$ & 110 \\
\hline Memorandos & $1965-1980$ & 33 \\
\hline Crachás & $1986-1995$ & 06 \\
\hline Documentos recebidos & $1958-1999$ & 133 \\
\hline Sem especificação & $1961-2000$ & 42 \\
\hline Total & & 1338 \\
\hline
\end{tabular}

Fonte:Arquivo Walter F.Piazza ${ }^{7}$

Muito significativo é o número de correspondências recebidas e guardadas. São cartas muito variadas, oriundas de vários estados do Brasil, de Portugal, México, Uruguai, Argentina, Estados Unidos, Colômbia, por exemplo, e que confirmam a internacionalização de seus trabalhos e atividades e, sobretudo, suas relações de força e prestígios no meio profissional. Tais fontes permanecem abertas e disponíveis para futuros pesquisadores. Uma primeira visada permite considerar que muitos dos textos das correspondências se mantém nos limites protocolares de uma escrita formal, mas isso não requer pesquisas mais vigorosas.

Foto 2 -Gaveta no IDCH/UDESC com as agendas

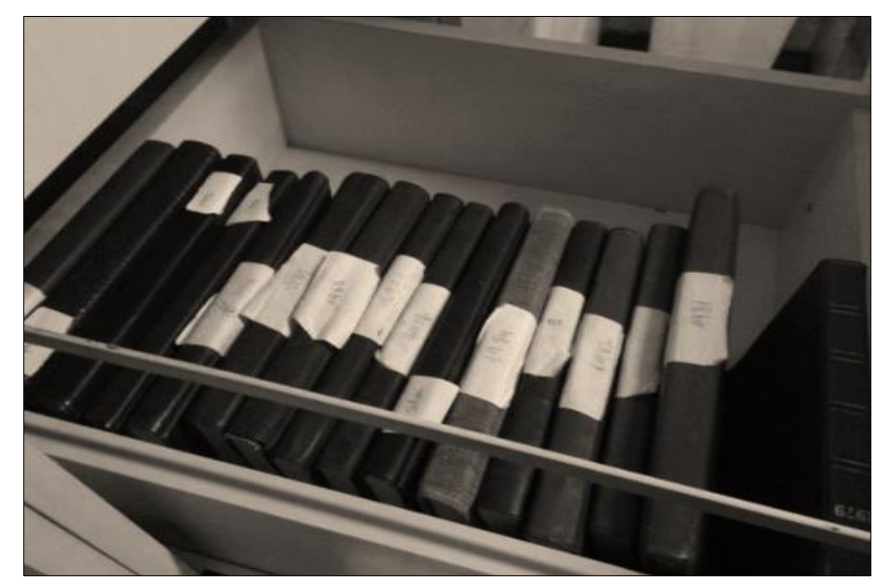

Fonte: Arquivo da autora

\footnotetext{
${ }^{6}$ Projeto de Pesquisa "Do manual ao digital: Arquivos pessoais de educadores catarinenses: Walter Fernando Piazza/Século XX”/ CNPq/FAPESC/UDESC. (Coordenação de Maria Teresa Santos Cunha)

${ }^{7}$ Levantamento geral realizado pela bolsista Amanda Preto Vioto/Curso de História /UDESC (2019/2020).
} 
Guardadas em gavetas, um conjunto de agendas pessoais- utilizadas entre 1978 e 1996 registram as mínimas e mais simples atividades cotidianas ligadas à sua atividade de professor (reuniões, participação em bancas de mestrado e doutorado, conferências, avisos burocráticos a serem dados, comentários); a acontecimentos familiares (aniversários, momentos de felicidade com a família, roteiro de viagens), ao registro de satisfações (descrição de homenagens e honrarias recebida). Ao registrar procedimentos cotidianos, abrem-se possibilidades de se reconhecer a relação orgânica entre aquele passado e o tempo presente, cotejando relações tanto pessoais como com as instituições públicas que aparecem citadas nas agendas.

Quase sempre com capa de couro, as agendas atuam como fontes onde o historiador pode buscar significar estas experiências sob o prisma da História da Educação, sobretudo aquelas anotações referentes à educação escolarizada, tais como: instituições citadas, cursos e conferências dados, participações em bancas de concurso, de mestrado e de doutorado, reuniões acadêmicas e políticas, homenagens recebidas. Tais anotações registradas no material arquivístico indicam diferentes indícios para rastrear redes de sociabilidades, conhecer diferentes experiências, traços de fatos narrados, ideias, opiniões e reações emocionais com relação ao ambiente universitário, atividades de ensino e pesquisa, seleção e indicação de bibliografias, críticas historiográficas, além das outras experiências registradas pelo ato da escrita.

Estes documentos da intimidade presentes em arquivos pessoais geram encantamento, entendido aqui como capaz de "de transmitir um sentimento arrebatador de unicidade, de evocar uma atenção exaltada", na perspectiva levantada por (GRENBLATT, 1991, p.250), também dão a ver as atividades cotidianas dos seus possuidores. Os estudos de Catherine Hobbs (2018) apontam sua importância para a pesquisa histórica:

arquivos pessoais documentam as atividades dos indivíduos, mas o que também fica neles registrados é a visão particular idiossincrásica e singular das pessoas quando estão fazendo as coisas que fazem e comentando a esse respeito. [...] são fontes de informações sobre a vida e as relações cotidianas e pessoais. São o lugar onde personalidade e fatos da vida interagem em forma documental (p.262).

Os estudos sobre agendas realizados por Ramos (2000) reforçam esta perspectiva e indicam que, ainda que possam ser considerados como documentos ordinários, elas ajudam a preservar uma certa identidade na forma de uma memória, uma língua, uma paisagem e um modo de vida. Para a autora:

Estes elementos dão às agendas o estatuto de "narrativas de si" e permitem que através delas se demarquem novos rumos dentro dos estudos auto-referenciais, pelo que elas têm de produção e construção textual, e por se acreditar que, tal como os diários, essas agendas recriam vidas, escrevem histórias, preenchem lacunas, tornando-se uma segunda coisa, mais refletida e emblemática (p.198).

Este artigo é tributário da intervenção atual (e ainda parcial) no arquivo pessoal de Walter Fernando Piazza e tem privilegiado estas fontes com o intuito de pensar aspectos de trajetórias de vida no tempo presente, a partir de documentos menores, negligenciáveis, em sua maioria. As agendas foram separadas, fotografadas e um mergulho nelas será uma das ações a serem realizadas, no prosseguimento da pesquisa, ainda em seu início. Através da desses vestígios documentais, busca-se dar sentido a estas experiências sob o prisma da História da Educação - como produto de uma construção cultural em articulação com sua dimensão social assumida por noções como 
representações, práticas e materialidade destes objetos culturais - (CARVALHO e PINTASSILGO, 2011); da História do Tempo Presente - que considera as experiências temporais da história e como "em cada presente, as dimensões temporais do passado e do futuro são postas em relação" (HARTOG, 2006, p.263). Consideram-se, também, diálogos na clave dos estudos sobre o Patrimônio Cultural pela análise das instâncias que custodiam e caracterizam arquivos pessoais como patrimônios histórico- educativos (MENEZES, 2005 e 2016).

No tempo presente, houve uma ressignificação das pesquisas sobre as artes de guardar que fez emergir novos paradigmas, voltados para o estudo das sensibilidades, dos testemunhos que caracteriza um retorno ao eu significante sem a pretensão de ser a chave da explicitação do sentido da história. Nesta perspectiva, o estudo com e dos arquivos pessoais remete a este movimento historiográfico em que há incentivo e liberdade de escolha de objetos e de maneiras peculiares de interpretá-los. Afinal, ninguém se aproxima desses materiais com olhos livres ou ingênuos e, sim, a partir de pontos de vista e problemáticas historicamente delineadas que derivam de um conjunto de questões que envolvem, igualmente, empiria, teorias, encantamentos e sensibilidades e têm como horizonte a perspectiva de uma intervenção no curso do mundo. $\mathrm{O}$ historiador pode ser um dos elos dessa passagem.

\section{2. “Deixo inteira liberdade ...”: o arquivo pessoal do professor Balduíno Andreolla (UFRGS)}

\subsection{Acercamentos do arquivo e de seu titular}

Ao investigar o arquivo pessoal do professor emérito da UFRGS, Balduíno Andreola, se reconhece, em seus gestos de guardar e de doar, indícios sensíveis de um intelectual, movido pelo desejo de manter vivas lembranças de suas ações na UFRGS. Armazenados em sacolas e pastas, estavam fragmentos de um tempo de experiência docente, organizados com delicadeza, como uma produção de si. Nesse processo de acumulação, misturam-se impressos e manuscritos alusivos aos diferentes lugares que Balduíno ocupou na Faculdade de Educação/UFRGS.

Um dos desafios, ao operar com esse papeis, é buscar compreender que espécie de arranjo o professor procurou imprimir nesse arquivamento, considerando as diferentes modalidades textuais, entendidas como dimensões de sua vida docente, que representam os diferentes lugares em que esteve na Faculdade. De acordo com Cox (2017), mesmo em meio a papeis aparentemente desordenados, podem-se localizar informações valorosas da memória do sujeito e da instituição na qual se inscreve, em suas palavras "a maneira como acumulamos e organizamos os documentos tem algo importante a nos dizer. O arquivo pessoal pode ser visto como um aspecto crucial do conhecimento de nós mesmos" (p.256). Essa questão trazida por Cox é absolutamente cara ao arquivo pessoal que aqui se examina. Assim, na documentação conservada, encontram-se desde bilhetes que recebia de colegas, correspondências, alguns poucos livros, convite de formaturas, programas de disciplinas, poemas de sua autoria, reportagens de periódicos, ofícios da Faculdade, textos impressos, muitos recortes da imprensa, panfletos de eventos acadêmicos, entre outros. Tendo como inspiração a letra de música de Chico Buarque "Todo o sentimento", entendese este conjunto documental como uma espécie de repositório de "um tempo que refaz o que desfez", ou seja, como uma tentativa de seu titular de recompor as experiências pretéritas, vividas na Universidade, por meio dessas práticas de arquivamento.

Antes de chegar ao arquivo propriamente dito, importa apresentar seu titular ${ }^{8}$. Balduíno nasceu em 1936, é o primeiro de onze filhos, vem de uma família de pequenos agricultores, de uma localidade chamada Fazenda Souza, hoje pertencente ao município de Caxias do Sul/RS.

\footnotetext{
${ }^{8}$ Para a apresentação do professor, foram consultados um texto autobiográfico (ANDREOLLA, 2015) e a entrevista concedida pelo professor ao Arquivo Histórico da FACED/UFRGS.
} 
Sobre o pai, diz o quanto amava a terra e não queria deixá-la, mas "com o avanço da urbanização em Caxias, a chácara teve que ceder às construções imobiliárias. E meu pai trabalhou dezoito anos como ronda noturno da Metalúrgica Abramo Eberle" $(2015$, p.56). A partir deste relato, amplia a reflexão, compara a vida de sua família às difíceis condições enfrentadas pelos pequenos agricultores, que, no passado e no presente, acabam abandonando o campo.

Ao meditar acerca de suas memórias familiares, percebe-se o quanto essas experiências produziram ressonâncias nas escolhas futuras de Balduíno, sobretudo nos temas de estudo que o mobilizam. Em suas palavras, "o meu compromisso com a educação popular, com as classes populares, com os movimentos sociais, vem também das minhas origens" (entrevista, 2012). Em seu arquivo pessoal, embora os documentos sejam datados do período de docência na UFRGS, esses sinais das camadas do tempo pretéritas ao ingresso na Universidade são perceptíveis pela quantidade expressiva de papeis que representam seu engajamento com as temáticas apontadas.

Foto 3- Professor Balduíno Andreola

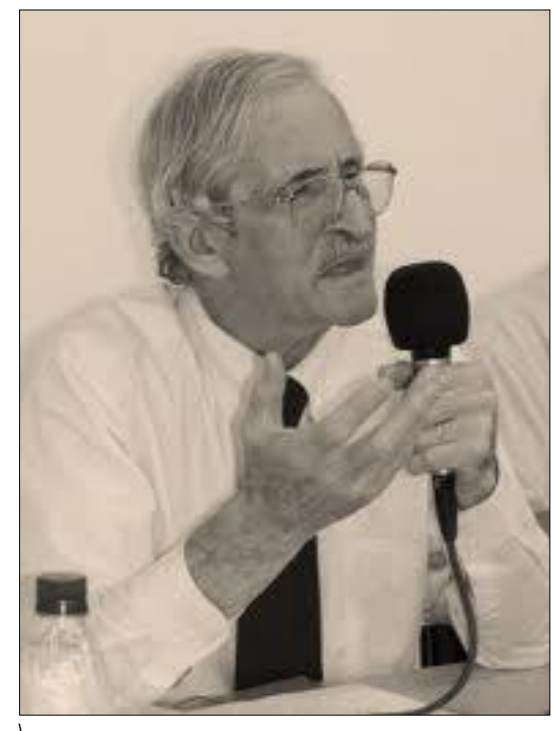

Fonte: Grupo de Estudos Paulo Freire - GEPFFaccat ${ }^{9}$.

$\mathrm{Na}$ entrevista que concedeu, Balduíno explicou seus percursos formativos. Foi sacerdote religioso durante quinze anos, vinculado à Congregação São José de Murialdo. Graduou- se em Filosofia e Teologia. Quando deixou a vida religiosa, decidiu pela continuidade da formação acadêmica. Assim, ingressou no Curso de Mestrado em Educação no Programa de Pós-graduação em Educação/UFRGS, em 1975, foi um dos primeiros alunos do Programa.

Balduíno, em 1978, fez concurso para a Faculdade de Educação/UFRGS, para a área de Filosofia da Educação e, neste lugar, ainda permanece ativo, mesmo tantos anos após sua aposentadoria. No início dos anos 1980, afastou-se da Universidade para cursar o Doutorado na Universidade Católica de Louvain, na Bélgica. Defendeu sua Tese de Doutorado em 1985, trata-se de uma pesquisa que relaciona o pensamento de Paulo Freire e de Emmanuel Mounier. Sobre sua trajetória na Faculdade de Educação, cabe dizer que esteve à frente da Direção entre 1988 e 1992. Aposentou-se em 1996, todavia, permaneceu vinculado à UFRGS como docente colaborador no Programa de Pós-graduação em Educação até 2003.É preciso considerar Balduíno como um sujeito importante nas memórias da UFRGS, sempre celebrado quando vêm à Faculdade. Por onde passa, "Baldô" irradia bem querer. Neste sentido, seu arquivo pessoal é permeado por afetos e sensibilidades.

\footnotetext{
${ }^{9}$ Disponível em: https://gepffaccat.wordpress.com/2013/11/20/paulo-freire-em-santo-angelo/. Acesso em 30. out. 2020.
} 


\subsection{Entre guardar e doar: dimensões do arquivo pessoal do professor}

Feita essa modesta apresentação de Balduíno Andreola, apresenta-se o lugar que abriga seus documentos pessoais, o Arquivo da FACED. Lá, se conservam memórias produzidas por essa instituição de formação docente, mas também relativas ao Colégio de Aplicação da Universidade, tendo em vista as aproximações de ambas as instituições durante muitos anos ${ }^{10}$. Em um espaço adaptado, estão acolhidos papeis de diferentes temporalidades, que passaram por diferentes mãos, muitos deles oriundos dos Departamentos da Faculdade ou dos setores administrativos do Colégio, outros tantos estavam nas casas de professores ou ainda esquecidos em seus armários na Faculdade ${ }^{11}$.

Como entender a atitude da doação do professor Balduíno? Esse gesto pode ser uma forma, mais ou menos intencional, de preservar uma imagem de si, de projetar-se, pode expressar um desejo de reconhecimento, de não ser esquecido, pois esses testemunhos, cedidos a um Arquivo, constroem uma imagem pública do que antes eram apenas nossos papeis (Ribeiro, 1998). Considerando a quantidade de guardados que se referem às memórias da Faculdade de Educação, pode-se também pensar no desejo dele em colaborar com a história desta instituição por meio da preservação desses papeis. Portanto, os incontáveis fragmentos de seu passado na Universidade, recolhidos em um trabalho de enredamento, foram tramados de forma a dar a este tempo pretérito uma imagem de seu titular e uma imagem da instituição na qual se inscreve. Entende-se que a entrega dessas materialidades ao Arquivo da Faculdade permitiu que adquirissem uma sobrevida, pois lá, cuidadas, transformam-se em documentos potentes para vários campos de estudos, entre eles a História da Educação.

Debruçar-se sobre tantos papeis exigiu, portanto, uma artesania do olhar, um exercício de atenção às sutilezas, às miudezas que por ele foram salvas do descarte. E, justamente, são nessas quase insignificâncias das experiências vividas que tornam raros os arquivos pessoais. O desejo de perscrutar o conjunto documental pode provocar sensações de perda, como diz Albuquerque Jr (2019), "na busca por conhecer, o primeiro gesto é de desconhecimento. Vai-se ao arquivo, mas ele não é reconhecido" (p.57). Assim, em meio a emoção provocada pelo manuseio dos papeis, é preciso estranhar, suspeitar... afinal, o que aquele processo de acumulação é capaz de indicar acerca deste professor? Em outras palavras, que diferentes dimensões do titular podem emergir da constituição de seu arquivo pessoal? (Heymann, 2013). Seguindo a reflexão de Albuquerque Jr (2019), entende-se o arquivo pessoal em questão como produção de si, com motivação memorial, e, na clave das sensibilidades ali depositadas, "como questão, como problema, como uma camada de tempo que condiciona a leitura daquilo que ele guarda" (p.58).

Durante a exploração inicial, observou-se uma capa de pasta em papelão firme com escritos do professor que denotam suas intenções de guarda e doação. Ele registrou:

pasta organizada há muito tempo. Não pude examinar, selecionar ou reorganizar agora o material. Deixo ao grupo de pesquisas da FACED a inteira liberdade de aproveitar ou eliminar o material de acordo com os objetivos da pesquisa. Porto Alegre 17/02/2014

\footnotetext{
${ }^{10}$ O Colégio de Aplicação foi inaugurado em 1954, idealizado pela professora Graciema Pacheco, cátedra da disciplina de Didática da Faculdade de Filosofia da URGS. Suas atividades foram realizadas em diversos espaços da universidade, no final da década de 1960, o colégio passou a dividir espaço com a recém-criada Faculdade de Educação. Sobre a história da instituição, ver Lima e Almeida (2016).

${ }^{11}$ Para maiores informações sobre o Arquivo Histórico da Faculdade de Educação/UFRGS, ver Almeida e Grimaldi, 2020.
} 
Da leitura dessas palavras, vê-se o desapego de Balduíno, que oferece "inteira liberdade", autorizando a equipe do Arquivo da Faculdade a cuidar de suas "relíquias" (Cunha, 2018), como melhor lhe aprouver. De qualquer modo, é possível que tenha feito escolhas entre os papeis antes de cedê-los, sabe-se das diferenças entre o que se vive, o que se registra, o que se guarda e o que se doa. Neste sentido, parece plenamente aceitável que Balduíno não tenha preservado tudo, provavelmente, em maior ou em menor medida, houve "censura, supressão, triagem, [...], silêncios, não ditos, interditos, deixando registros que permitam a elaboração futura de uma biografia edificante" (Mignot, 2005, p.56). Como diz Albuquerque Jr, o arquivo "instaura uma lei de seleção, da designação do que é arquivável ou não" (p.60).

E assim, enquanto os papeis iam sendo higienizados e catalogados, emergiram possíveis categorias de análise. Constatou-se a presença de muitos documentos relativos ao tempo que Balduíno esteve como Diretor da Faced, outros representam seus interesses epistemológicos, especialmente vinculados ao pensamento freireano, à educação popular, educação do campo, ao Movimento Sem Terra, à educação étnico-racial. Há materiais que identificam o professor em suas aulas, na graduação e pós-graduação, também documentos que se referem à sua participação como membro do Conselho da Universidade (CONSUN). Outrossim, conservou impressos da vida institucional da Faculdade, do Programa de Pós-graduação em Educação, do Diretório Acadêmico da Faculdade e do Diretório Central dos Estudantes. Localizam-se também evidências de suas redes acadêmicas, bem como documentos referentes a eventos científicos que participou, convites para palestrar, correspondências entre colegas e pesquisadores de outras instituições. Ainda, papeis que indicam sua participação nos sindicatos dos professores universitários (ADUFRGS e ANDES) e aqueles que denotam as relações que mantinha com o sindicato dos professores do Estado (CPERS). E, por fim, poesias, em que medita sobre a Faculdade/Universidade e sobre as pessoas que lá estavam.

Neste garimpo, é comovente um conjunto documental sensível que diz respeito a outro professor, Alceu Ferraro, seu colega na Faculdade. Neste conjunto, constam vários registros do processo de candidatura e eleição de Alceu Ferraro para Reitor da UFRGS, em 1988, e seus desdobramentos, pois, mesmo tendo sido indicado pela comunidade universitária, Ferraro foi impedido pelo Governo Federal de ocupar a posição de Reitor. $\mathrm{O}$ fato de Balduíno manter uma quantidade expressiva de papeis alusivos à outra pessoa é incomum nos arquivos pessoais, indica sentimentos de amizade, alteridade e de cuidado com seu colega em um momento importante e triste da história da Universidade, uma memória pouco conhecida pelas novas gerações.

Sendo assim, metodologicamente, procurou-se construir núcleos narrativos entre os documentos, sobretudo no que diz respeito às práticas de guardar e guardar-se. A partir dessas perspectivas, o texto avança na descrição e análise do arquivo pessoal, com vistas a aprofundar as discussões em torno das memórias em papel de Balduíno Andreola.

\section{As delicadezas deste arquivo pessoal}

Entende-se o conjunto documental do professor Balduíno na percepção das subjetividades implicadas, portanto, um dos modos de perscrutá-lo é na clave de suas delicadezas. A intenção é encontrar a "poética do arquivo" (Albuquerque Jr, p.67), considerando -o um "reduto de sensibilidades" (Cunha, 2019). Procurou-se esmiuçar os indícios, localizar valores simbólicos, passíveis de identificação na documentação.

Pesavento (2007) define a pesquisa que opera com o conceito de sensibilidades como algo que se assemelha à "leitura da alma". É por meio das experiências pessoais arquivadas que reverberam "práticas culturais do sensível" (p.15). A autora explica o quão difícil pode ser capturar tais evidências "pois se inscrevem sob o signo da alteridade, traduzindo emoções, sentimentos e 
valores que podem não ser mais os nossos" (p.15), ou seja, como historiadores, é importante que se reeduque o olhar para melhor aproximação do passado, na intenção de estranhá-lo.

Nesta perspectiva do estranhamento, ao ler bilhetes e cartões que o professor preservou, percebe-se o quanto nossas práticas cotidianas de comunicação, dentro e fora das instituições, alteraram-se, em pouco mais trinta anos. Por que Balduíno guardou esses singelos papeis que carregam memórias da convivência docente na Faculdade? Seria este um hábito comum entre professores? Seria este um modo de poder revisitar um tempo importante de sua trajetória? Como possível resposta, vê-se nessa conservação desses registros comuns a constituição de uma experiência do sensível, em que o titular do arquivo pessoal exprime suas afeições, por meio de seus guardados.

\section{Foto 4}

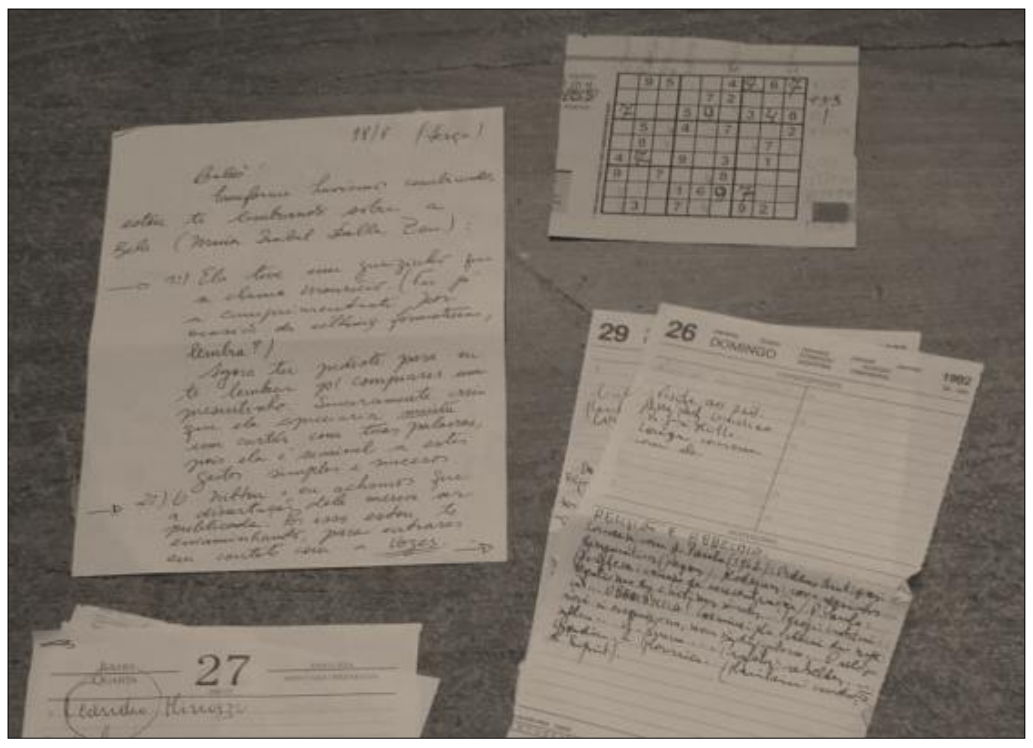

Fonte: Arquivo pessoal professor Balduino Andreola

E especificamente sobre bilhetes, o que se pode dizer sobre a quase insignificância desses artefatos, efêmeros, pouco explorados pela historiografia? Trata-se de um gênero discursivo que se inscreve nas modalidades de escrita epistolar. Assim como as cartas, são enviados para encurtar distâncias, fornecem pistas para compreender tanto quem as escreveu, quem as recebeu e o contexto no qual foram produzidos (Bastos, Cunha, Mignot, 2003). E por não terem sido jogados fora, permitem que se estime a dimensão que ocupam na memória de seu titular/destinatário. Os bilhetes comportam protocolos e gestualidades comuns às cartas, respeitam convenções de escrita, como linguagem de cortesia, de saudação e encerramento. Entretanto, por se tratarem de comunicações ágeis, correspondem a mensagens breves, reduzidas ao essencial, feitas no calor da hora, sem maiores preocupações com o esmero, tanto na forma como no conteúdo, em que se aproveita o suporte de escrita que estiver mais ao alcance das mãos.

A escrita de bilhetes é uma prática cultural, de longa data. Sua circulação, do mesmo modo que as cartas, está relacionada ao desenvolvimento do acesso à cultura escrita na vida urbana e isso data de alguns séculos atrás. $\mathrm{Na}$ contemporaneidade, manifesta-se no uso da escrita fugaz em telas de aparelhos celulares, mas, nos anos que Balduíno esteve na Faculdade da Educação, revestia-se de outros formatos. Esses papeizinhos foram armazenados por ele em sacos plásticos, grande parte é bastante difícil de decifrar. Muitos deles se referem ao período em que esteve no lugar de Diretor da 
Faced, vários foram escritos pela vice-diretora, Aldanei Areais. Mas conservou também aqueles enviados por diferentes colegas, que tratam de assuntos diversos.

Dessas mensagens que Aldanei encaminhava a Balduíno, observa-se a preocupação em produzir registros objetivos, provavelmente com vistas a melhor informar o Diretor sobre os assuntos tratados. Em todos, despede-se com um abraço, coloca a data o horário. Muitos foram escritos à noite. Às vezes, ela enumera os assuntos, no sentido de ordená-los. Entretanto, talvez pela proximidade com o remetente, não escreve de modo formal e sim deixa transparecer seus sentimentos. Em um deles, Aldanei apenas escreve "dá-lhe Tio Baldô!" (04/08/89), em outro faz cobranças, "Baldô, ainda não fizeste a mensagem de fím de ano! Pô Baldô!!! Por aonde anda tua inspiração? Temos até sexta feira para encaminhar, 16/12, 18h30". Ao que tudo indica, ele cumpriu a tarefa, pois guardou a mensagem "Fim de ano FACED", em que consta o poema "Cadê a estrela de natal?", provavelmente seria a resposta esperada pela comunidade.

Chama atenção um desses papeis ordinários, escrito pelo assessor da Direção, servidor Emílio Millan Neto, "Aviso, de: Emilio para Baldô", em tom de ironia diz, "eu sempre desconfiei que tu tinhas interesse na privatização, agora foi confirmado, até cursinho 'os caras' vão te dar". Acompanha o bilhete a programação do evento "Como participar na privatização de empresas estatais?”, endereçada ao Diretor da Faculdade. Trata-se de uma correspondência própria dos anos 1990, tempos difíceis para a Universidade pública, em que o discurso neoliberal insuflava as privatizações, emergindo com força tanto no Estado como em nível nacional. As convicções políticas de Balduíno, como sabemos, estavam de encontro à essa proposta, por isso a ironia do remetente do texto.

É relevante destacar mais alguns desses escritos que foram remetidos a Balduíno por professores, enquanto estava na função de Diretor da Faculdade. Em um deles, diz uma professora, "Baldô, como foi a viagem? Agradeço teu empenho no meu processo...". Com essas palavras, evidencia um gesto de reconhecimento pela ajuda do Diretor nas questões burocráticas de sua vida funcional como servidora pública. Em outro, a notícia do nascimento do filho de uma professora, "ela teve um gurizinho (tu já a cumprimentaste por ocasião da última formatura, lembra?). Agora, tu pediste para eu te lembrar para comprar um presentinho. Sinceramente, creio que ela apreciaria um cartão com tuas palavras, pois ela é sensível a estes gestos simples e sinceros". Nesse bilhete, percebe-se a amabilidade de Balduíno, seus cuidados com os colegas, que se manifestam na preocupação de não esquecer a professora que acabava de dar à luz a um bebê. No caso específico, pediu ajuda a colega Beatriz Fischer. É possível que ele tivesse por hábito acionar diversas pessoas para que lhe lembrassem dessas situações cotidianas, humanas, que podem facilmente ser esquecidas diante das muitas demandas de trabalho.

Ainda na busca por evidências do sensível em correspondências, vê-se que o titular do arquivo pessoal examinado guardou algumas enviadas pelo colega/amigo Nilton Fischer. Esses dois professores construíram laços, desde o ingresso no Mestrado no PPGEDU/UFRGS, alimentados pela partilha de posições políticas e epistemológicas. Entre os anos 1980 até início dos anos 2000, atuaram como professores orientadores na Linha de Pesquisa "Educação e Classes Populares"12

Assim, no texto escrito à mão, em folha timbrada da $\mathrm{ANPED}^{13}$, Nilton escreve "Amigo Baldô" e informa sobre um Encontro com lideranças do Partido dos Trabalhadores (1991). Em uma mensagem enviada por Nilton, a personagem central é a então hoje Deputada Federal Maria do Rosário, estudante egressa do Curso de Pedagogia da Faced. O

\footnotetext{
${ }^{12}$ Balduíno guardou uma lista com nomes dos professores vinculados ao Programa de Pós graduação em Educação, de 1992, incluindo o número de vagas de orientação e nomes dos alunos selecionados. Nesta lista, localizo a informação que ambos atuavam como professores orientadores na Linha de Pesquisa "Educação e Classes populares".

${ }^{13}$ Nilton Bueno Fischer teve uma ativa participação na ANPEd. Ocupou a vice-presidência da Associação nas gestões de 1983-85/1995-97/1997-1999. Exerceu a função de Secretário Geral nas gestões de 1989 a -1993. E atuou no Conselho Fiscal da entidade entre 1993-1995.
} 
texto diz "Balduíno, a Maria do Rosário é nossa aluna, ela foi eleita vereadora e não fizemos nenhuma manifestação. Agora, talvez possamos reparar o deslize, aproveitando este 'ensejo', não achas que um cartãozinho viria bem?" Junto, está um material do Partido Comunista do Brasil (PCdoB), indicando a eleição da vereadora, em 1992. A manifestação do professor deixa clara a importância da Faculdade, institucionalmente, valorizar as conquistas de seus estudantes, ainda mais considerando que a recém eleita vereadora partilhava de convicções políticas que a aproximavam de Balduíno e de Nilton. Talvez por isso a preocupação deste em reparar o esquecimento da Faced.

Por meio de escritos mais longos, Nilton Fischer se dirige a Balduíno para discutir questões da Faculdade e do Programa de Pós-graduação, referindo-se ao destinatário com a expressão "Amigo Balduíno" ou "Amigo fraterno Balduíno". Na correspondência de 27/01/1984, o remetente apresenta uma série de orientações, pois o colega ocuparia seu lugar na função de coordenação interina do Programa de Pós-graduação. Balduíno parece ter lido atentamente, pois fez inscrições no texto, circulou várias orientações, como as questões de segurança, limpeza, ajardinamento do pátio. É um documento precioso para entender como se dava a gestão do PPGEDU nos anos 1980. Em outra carta, do início de 1988, escrita no computador ou talvez em máquina elétrica, Nilton chama a atenção para a convivência de ambos desde o Curso do Mestrado, tendo Paulo Freire como a grande referência que os aproximou. Saúda a eleição de Balduíno para a Direção da Faculdade e pergunta sobre sua disponibilidade para prosseguir como docente do Programa, estimulando-o a permanecer.

Percorrendo rastros de delicadeza no arquivo pessoal, observa-se que os eventos natalinos parecem ter sido momentos significativos para o professor, pela quantidade de guardados alusivos a essas comemorações. Dessas "festas de Natal", Balduíno manteve cartões que recebeu dos colegas e cópias dos roteiros das celebrações que aconteciam, conduzidas por ele durante o tempo em que esteve como Diretor da instituição. Seriam esses eventos uma prática efetivada em sua gestão? Teriam relação com sua história de vida, como uma herança do tempo em que foi sacerdote religioso? Quais os significados de promover festejos de Natal em uma instituição laica? Quando essas atividades foram abandonadas, considerando que hoje não existem mais?

Sobre esses eventos, localizei um poema de autoria do professor, "Natal hoje", referente ao natal 1989 e dirigido à comunidade facediana. Nos versos, o discurso religioso mistura-se à adesão ao discurso político, ao trazer enunciados do passado para o presente, assim, a história do nascimento de Jesus se funde às histórias de muitas crianças em situação de abandono no Brasil. A mensagem natalina, dirigida a servidores e estudantes da Faculdade, assume o tom de denúncia, em que, segundo o autor, hoje "são outros cristinhos, sem pão, sem afeto", localizados em regiões periféricas de Porto Alegre, e de tantas outras cidades, que simbolizam a história do nascimento de Jesus. Por um lado, a permanência do pensamento religioso cristão, por outro, o engajamento nas causas sociais, o compromisso com as pautas de educação popular. Esses elementos se imbricam na construção do poema.

Ainda com relação aos cartões de natal, Balduíno guardou dois deles que foram enviados pelo Colégio de Aplicação para a Faculdade, um de 1989 e outro de 1992. O primeiro traz um desenho de aluno do Colégio na primeira página, na mensagem um destaque para 0 trecho "acreditamos que a competência e o sentido humano que emana do "alto" de nosso prédio se aliará ao nosso "bom astral" e a positividade brilhará todos os dias, fazendo da nossa energia uma fonte de bem viver", assina o Diretor Jorge Barreto. É bem possível que fosse um protocolo de civilidades essa troca de cartões entre Direção da Faculdade e do Colégio, entretanto, observa-se um reconhecimento à pessoa do Diretor Balduíno que parece ir além das palavras usuais que se usam por força do dever do ofício. No primeiro cartão, o destaque "à competência e sentido humano que emanam do alto do prédio". Ora, a sala da direção localizase no nono e último andar do prédio azul, é lá que trabalhava Balduino Andreola. No segundo 
cartão, explicita-se o reconhecimento ao carinho e conduta ética do Diretor nas questões que envolviam o Colégio. Pode-se pensar que Balduino, enquanto Diretor da Faced empenhou-se em construir um ambiente de harmonia nas tensas relações que historicamente envolviam duas instituições distintas que habitavam o mesmo espaço verticalizado.

Seguindo o tema do "Natal", identificou-se outro bilhete da colega Beatriz Fischer junto a um texto intitulado "Meu natal", de autoria da professora Maria Bernadette Rodrigues. Ao final, Beatriz escreveu "Baldô, Aldanei e Emílio: Feliz Natal! A Ivany e eu descobrimos este texto da Bernadette e achamos que deveria ser divulgado entre nós. Compareçam ao corredor do oitavo andar e vejam os demais textos dos colegas. Vale à pena ler!". Então, o que se percebe é que havia um movimento dos docentes da Faculdade em torno da comemoração natalina, pouco comum atualmente, em que se exibiam textos escritos por eles, prática talvez fomentada por Balduíno, mas que, possivelmente, não se restringia a uma atividade meramente institucional.

Para além dessas memórias, Balduíno guardou um cartão do Movimento Sem Terra com os dizeres, "ocupar, resistir, produzir também na educação, que em 1992 a gente possa assumir junto esta bandeira", evidenciando sua afeição em relação à causa do MST.

E com relação ao final de sua gestão como Diretor da Faculdade, também há cartões de elogios ao seu trabalho que foram guardados. Em um deles, a colega Vera Moraes registra, "é bom trabalhar contigo!". Conservou uma circular de dezembro de 1992, referente à solenidade de transmissão do cargo de Diretor para a professora Maria Isabel Bujes. Nesta circular, constam as informações sobre a confraternização de fim de ano, tal evento, que marca o fim do tempo da Direção de Balduíno, aconteceu no Morro do Sabiá, um lugar à beira do Guaíba. Ao final da folha, está escrito, "e que tudo floresça em 1993", típico dos modos de expressão do titular do arquivo pessoal. $\mathrm{O}$ texto apresenta um detalhamento da atividade que seria realizada, destaca-se a promoção de "jogos, sorteios, homenagens". Solicitam-se doação de brindes "que possam animar as atividades", explica-se que haverá caronas e até o cardápio foi divulgado "galeto, costela, salsichão e saladas". Por fim, na intenção de estimular a participação de todos os servidores, comunica-se "o preço está bem razoável: alguns pagarão um pouco mais para subsidiar, até mesmo isentando outros de pagamento."

Nesses guardados, conservou o que para ele tinha significado. Reuniu memórias felizes em pequenos papeis, ordinários, singelos, despretensiosos, que, precipitadamente, poderiam ter sido descartados. Não foram. Resistiram à passagem dos anos e hoje se anunciam como um "tempo de delicadezas", voltando mais uma vez à canção de Chico Buarque que ilumina essas reflexões.

\section{Inacabamentos...}

Sob a história, a memória e o esquecimento. Sob a memória, o esquecimento, a vida. Mas escrever a vida é outra história. Inacabamento. (RICOEUR, 2007, p.513).

Sem pretensão de escrever a vida, o contato, os cuidados com a conservação e a pesquisa nos arquivos pessoais de Walter Fernando Piazza (UFSC) e Balduíno Antonio Andreola (UFRGS), evocam, como fontes, imperativos éticos de memória e esquecimento. Arquivos pessoais criam oportunidades para que se reinventem temas e modos manejados por abordagens transdisciplinares e mobilizados por procedimentos imaginativos e teóricos, não raro, heterodoxos, como estar atento às sutilezas, às miudezas arquivadas. Absurdamente humanos, seus usos são tantos e tão diversos que se torna difícil tratá-los como um todo. Por mais que se tente classificar, separar, arrumar, perguntar, duvidar, eles têm suas forças como fontes inovadoras da ciência social contemporânea. Inúmeras inquietações assolam os pesquisadores, em especial os historiadores e, certamente, não se esgotarão neste trabalho, mas poderão desenhar outros contornos ao tema. 
Consultar materiais em variados suportes para pensar aspectos do fazer-se desses dois professores, tendo a palavra escrita como ferramenta, foi o desafio inicial. O empreendimento de se consultar e de se escrever sobre estes professores, a partir de seus arquivos pessoais, em que pese a seleção criteriosa de problemáticas a enfrentar, faz aflorar variadas questões, como, por exemplo: Que documentos selecionar no frenesi documental? Que ganhos e perdas relatar? Há convicção de que não há respostas definitivas, mas, igualmente, um desejo muito humano de evidenciar uma postura metodológica esclarecedora e despretensiosa como fecho. Ao relatar o que cada professor concretizou, é fundamental não esquecer de que as vidas das pessoas não são somente aquilo que se registrou; que cada trajetória se compõe também de perdas e de omissões, de desejos irrealizados, do que não foi escolhido, de numerosas possibilidades que em sua maioria nem chegaram a se realizar, dos medos que paralisam e até a consciência do que teria sido abandonado nos projetos, nas ações, nas oportunidades.

Referindo-se às trajetórias docentes, Nóvoa (1992) postula que "esta profissão precisa de se dizer e de se contar: é uma maneira de a compreender em toda a sua complexidade humana e científica" (p.10). Podemos dizer que os estudos acerca da profissão de professor conservam, no tempo presente, seu lugar no campo da História da Educação. E, neste sentido, a imersão nos arquivos pessoais de Walter Piazza e de Balduíno Andreola permite que se perscrutem seus itinerários, nas interfaces com as instituições em que estiveram como professores. Portanto, como espaços de investigação histórica, os dois conjuntos documentais conservam memórias autobiográficas, em meio às memórias das Universidades. Talvez o que mais impressione seja que os arquivos em questão transcendam a existência desses homens, pelos múltiplos cruzamentos de sujeitos e acontecimentos reunidos em suas práticas de arquivamento pessoal.

Musealizados nos locais de salvaguarda, o IDCH/UDESC e o Arquivo da Faced/UFRGS, os arquivos pessoais dos professores Walter Fernando Piazza e Balduíno Antonio Andreola, aguardam outros olhares que os vejam, ainda mais, como fontes e como acontecimentos. O tempo de parte de suas vidas que aqui voltou, pela narrativa, espera-se que seja um sinal do radar do tempo presente que, enviado ao futuro, aponte a necessidade e a transcendência de outras leituras possíveis, já que esta assume seu lugar de inacabamentos.

\section{Referências}

ALBUQUERQUE JR, Durval Muniz. O Tecelão dos Tempos: novos ensaios de Teoria da História. São Paulo: Intermeios, 2019.

ALMEIDA, Doris Bittencourt; GRIMALDI, Lucas. Entre gestos de guardar e atos de testemunhar: o Arquivo de memórias da Faculdade de Educação/UFRGS. Educação em Revista, v.36, 2020. DOI: https://doi.org/10.1590/0102-4698223025.

ANDREOLA, Balduíno Antonio. Biografia intelectual de Balduíno Antonio Andreola. Revista Pedagógica. Chapécó, v.17, n.36, p.51-68, 2015. DOI: https://doi.org/10.22196/rp.v17i36.3147.

ASSMANN, Aleida. Espaços de Recordação: formas e transformações da memória cultural. Campinhas/SP: Unicamp, 2011.

BASTOS, Maria Helena Camara; CUNHA, Maria Teresa Santos; MIGNOT, Ana Chrystina Venancio. Destino das Letras: história, educação e escrita epistolar. Passo Fundo: EDUPF, 2003.

BELLOTTO, Heloísa Liberalli. Arquivos: estudos e reflexões. Belo Horizonte: Editora UFMG, 2017.

BELLOTTO, Heloísa Liberali. Tratamento Documental. Rio de Janeiro: Editora FGV. 2006. 
CARVALHO, Marta Maria Chagas; PINTASSILGO, Joaquim (Org). Modelos Culturais, Saberes Pedagógicos, Instituições Educacionais: Portugal e Brasil, Histórias Conectadas. São Paulo: EDUSP, 2011.

COX, Richard. Arquivos Pessoais: um novo campo profissional - leituras, reflexões e reconsiderações. Belo Horizonte: Editora UFMG, 2017.

CUNHA, Maria Teresa Santos. (Des)Arquivar: arquivos pessoais e ego-documentos no tempo presente. São Paulo: Florianópolis: Rafael Copetti Editor, 2019.

CUNHA, Maria Teresa Santos. Entre Netuno e Clio: primeiras aproximações às cartas do Almirante Henrique Boiteux (Santa Catarina/Século XX). Revista Brasileira de Pesquisa (Auto)Biográfica, Salvador, v.3, n.9, 2018.

FOUCAULT, Michel. Nietzche, a genealogia da História. In: FOUCAULT, Michel. Microfísica do Poder. São Paulo: Graal, 2008.

GOMES, Ângela Maria de Castro. Nas malhas do feitiço: O historiador e os encantos dos arquivos privados. Revista Estudos Históricos, Rio de Janeiro, v.11, n.21, p. 121-128, jul.1998 GREENBLATT, Stephen. O novo historicismo: ressonância e encantamento. Estudos Históricos, Rio de Janeiro. v. 4, n. 8, p. 244·261, 1991.

HEYMANN, Luciana, De "arquivo pessoal' a "patrimônio nacional": reflexões acerca da produção de " legados". In: Seminário PRONEX Direitos e Cidadania, 1, 2005, Rio de Janeiro. Anais Eletrônicos... Rio de Janeiro: CPDOC, 2005. Disponível em: https://cpdoc.fgv.br/producao_intelectual/arq/1612.pdf/. Acesso em 20 out. 2020.

HARTOG, François. Tempo e patrimônio. Varia Historia, Belo Horizonte, v.22, n.36, p.261273, jul-dez.2006. Disponível em: http://www.scielo.br/pdf/vh/v22n36/v22n36a02.pdf. Acesso em 21 out. 2020. DOI: https://doi.org/10.1590/S0104-87752006000200002.

HARTOG, François. Evidência da História. O que os historiadores vêem. Belo Horizonte:Autêntica Editora,2011.

HEYMANN, Luciana. Arquivos Pessoais em perspectiva etnográfica. In: TRAVANCAS, I. R.; HEYMANN, L.(Org.) Arquivos pessoais: reflexões multidisciplinares e experiências de pesquisa. Rio de Janeiro: Editora FGV, 2013, pp 29-42.

HOBBS, Catherine. ' $O$ caráter dos arquivos pessoais: reflexões sobre o valor dos documentos de indivíduos'. In: Pensar os arquivos/Uma antologia. Luciana Heymann e Letícia Nedel, organizadoras; Rio de Janeiro: FGV Editora, 2018, p. 261-274).

KOSELLECK, R. Estratos do tempo: estudos sobre História. Rio de Janeiro, Contraponto, 2014.

LIMA, Valeska Alessandra de; ALMEIDA, Dóris Bittencourt. O Colégio de Aplicação/UFRGS e a difusão das classes experimentais secundárias: entre o arquivo e a memória oral (1959-1981). Revista História da Educação, v.22, n.56, p.207-227, set./dez. 2018. DOI: https://doi.org/10.1590/2236-3459/77345. 
MENEZES, Maria Cristina (Org). Desafios Iberoamericanos: O Patrimônio Histórico Educativo em Rede, São Paulo: CME/FEUSP, 2016. DOI: https://doi.org/10.11606/9788560944651.

MIGNOT, Ana Chrystina Venancio. O carteiro e o educador: práticas políticas na escrita epistolar. Revista Brasileira de História da Educação, São Paulo, n.10, p. 45-69, jul./dez. 2005.

NÓVOA, Antonio (Org). Vidas de professores. Porto: Porto Editora, 1992.

PESAVENTO, Sandra Jatahy. Sensibilidades: escrita e leitura da alma. In: PESAVENTO, Sandra Jatahy; LANGUE, Frédérique. (Org.). Sensibilidades na história: memórias singulares e identidades sociais. Porto Alegre: UFRGS, 2007.

RAMOS, Tania Regina de Oliveira." Querido diário: Agenda é mais moderno". In: MIGNOT, Ana Chrystina; BASTOS, Maria Helena Camara; CUNHA, Maria Teresa Santos. (Org.). Refúgios do Eu. educação, história, escrita autobiográfica. Florianópolis: Editora Mulheres, 2000. p. 191-201.

RICOEUR, Paul. A memória, a história, o esquecimento. Campinas: Unicamp, 2007.

ROUSSO, Henry. A última catástrofe: a história, o presente, o contemporâneo. Rio de Janeiro: FGV, 2016. 